\title{
Research on the Development Path of E-Commerce Logistics in China from the Perspective of Environmental Protection
}

\author{
Keqiang Zhu* \\ School of Circulation and Commerce, Woosuk University, Jeonju, Jeollabuk-do, Korea \\ *Corresponding author. Email: 1564859552@qq.com
}

\begin{abstract}
In recent years, with the rapid development of e-commerce industry in China, the supporting e-commerce logistics is growing rapidly. At the same time, a large number of express packages also cause serious waste of resources and environmental pollution. Environmental protection is the inevitable trend of the development of logistics industry and the future development direction of e-commerce logistics industry, but there are still many problems in the current environmental development of e-commerce logistics in China. This paper puts forward corresponding countermeasures and suggestions for these problems, in order to provide some useful reference for the cleanliness development of e-commerce logistics in China.
\end{abstract}

Keywords: logistics, environmental, e-commerce, greenization

\section{INTRODUCTION}

Jinping Xi pointed out that "adherence to environmental development is a profound revolution in the development view. We should take extraordinary measures from changing the mode of economic development, comprehensive treatment of environmental pollution, intensive utilization of resources, and improving the system of ecological civilization." That is to say, while pursuing economic development, we should make rational use of resources, pay attention to environmental protection and take the road of sustainable development. However, with the rapid development of e-commerce logistics industry, it also causes a huge waste of resources and serious environmental pollution, which is not in line with the requirements of environmental development. For the sustainable development of e-commerce industry, it is necessary for e-commerce industry to introduce environmental logistics.

\section{The necessity of implementing environmental e-commerce logistics in China}

Environmental logistics refers to the use of advanced logistics technology to plan and implement logistics activities such as transportation, storage, packaging, loading and unloading, circulation and processing, aiming at reducing environmental pollution and resource consumption. It refers to the greenization of the whole process of logistics operation and logistics management, mainly including the greenization of circulation processing processes such as environmental storage, greenization packaging and greenization transportation[1].

With the continuous development of the world economy, the living environment of human beings is also deteriorating, which is embodied in energy crisis, resource depletion, expansion of the ozone layer hole, environmental pollution and ecosystem imbalance. Taking environmental pollution as an example, air pollution in more than 20 mega cities in the world exceeds the standards set by the World Health Organization. Up to now, the governments of all countries in the world have fully realized the importance of environmental development. Specifically, in the logistics industry, they have issued special policies, laws and regulations to promote the development of environmental logistics to guide the environmental protection behavior of enterprises. For example, the main countries in Europe and the United States take ISO14000 environmental certification standard as the passport to enter their own market, and green environmental protection as a non-tariff wall Base. As a large foreign trade country with $80 \%$ dependence on foreign trade, the implementation of environmental logistics is particularly important to us. It not only affects the development direction of logistics industry in the future, but also becomes a bottleneck restricting the development of foreign trade in the future. Especially in the new situation of rapid development of cross-border ecommerce in China, express logistics brought by crossborder e-commerce B2C(Business-to-Consumer) has become an important part of China's logistics industry. Therefore, environmental e-commerce logistics has become an inevitable requirement for the sustainable development of modern logistics in China, and the specific data is shown in Table 1. 
Table 1: 2015-2019 Quantity of E-commerce Logistics Package

\begin{tabular}{|c|c|c|c|c|c|c|}
\hline Year & $\mathbf{2 0 1 4}$ & $\mathbf{2 0 1 5}$ & $\mathbf{2 0 1 6}$ & $\mathbf{2 0 1 7}$ & $\mathbf{2 0 1 8}$ & $\mathbf{2 0 1 9}$ \\
\hline $\begin{array}{c}\text { Quantity } \\
\text { (Billion) }\end{array}$ & 139.6 & 206.7 & 313.5 & 400.6 & 505 & 635.2 \\
\hline
\end{tabular}

*Data sources: China Report Network

\section{PROBLEMSINTHEENVIRONMENTAL DEVELOPMENTOFE-COMMERCELOGISTICSINCHINA}

China's logistics industry started late, and the service level and research of environmental logistics are still in the initial stage. There is a big gap in the concept, policy and technology between China and advanced countries in the world in environmental logistics. There are mainly the following problems.

\subsection{Relatively weak concept of environmental logistics}

On the one hand, the guiding ideology of environmental logistics of some government functional departments has not been fully established. Some local governments pursue local GDP indicators unilaterally, lack of foresight for environmental development including logistics industry, and there is a gap with the pace of the times. On the other hand, operators and consumers are still weak in the concept of logistics environmental management. Although there are a large number of e-commerce logistics enterprises in China, most of them lack correct understanding of environmental logistics due to their small scale, backward technology and outdated concept. Many enterprises are reluctant to develop environmental logistics in order to pursue economic benefits unilaterally and satisfy with the traditional logistics mode. Even if some enterprises are willing to participate in environmental logistics, they are only doing environmental logistics as an image project, lacking substantive measures. At present, China's consumers' environmental consciousness of logistics is generally not strong. From the perspective of the whole society, there is still a lack of a strong environmental environment atmosphere, and it is difficult to form a situation of national participation. For example, for e-commerce express packaging, some consumers have a weak awareness of environmental protection. After receiving the package, they often put it into the garbage can indiscriminately. Although some consumers want to sort it out, they can only stop because they lack the infrastructure for e-commerce packaging and recycling. There are also consumers in sending packages, unnecessary over packaging of goods, resulting in waste of packaging materials.

\subsection{The guidance and supervision functions of the government are not fully exerted}

Environmental logistics is an important part of today's sustainable economic development, which is of great significance to the continuous development of social economy and the continuous improvement of human life quality. The government should build a environmental logistics development framework, and do a good job in the guidance and policy construction of environmental logistics development. At present, the governments of many developed countries have not only formulated relevant policies and regulations to control the logistics pollution, but also paved the way for the environmental logistics from the reasonable layout of the logistics industry development, so as to improve the circulation function of the city and enhance the environmental function of the city logistics [2]. Although China has been committed to the formulation and promulgation of policies and regulations on environmental pollution since the 1990s, there are not many laws and regulations for the logistics industry, and there are many legal blind areas for environmental logistics laws and regulations. Some local governments have formulated some development strategies for environmental logistics, but due to the policy preference for overall guidance and lack of specific implementation rules, many policies and regulations are not implemented in place and the implementation effect is not ideal in the specific implementation process. In addition, the local government has not implemented the green environmental protection supervision, and the cost of enterprises' violation of laws and regulations is low, which is easy to cause fluke psychology. In other places, the lack of incentive policies for environmental logistics leads to the low enthusiasm of enterprises to participate in environmental logistics.

\subsection{Imperfect evaluation system of environmental logistics}

At present, there is still a lack of evaluation standards and methods for environmental logistics in China. The evaluation system of environmental logistics is not perfect. There is no environmental evaluation system for the operation links of enterprises, such as packaging, transportation, storage and circulation. Some enterprises want to participate in environmental logistics, but they do not know how to carry out the environmental transformation of logistics, which restricts the development of environmental logistics[3]. For example, in the aspect of packaging environmental, there is no specific standard for environmental packaging materials, and there is no unified standard for packaging specifications, which leads to different packaging materials and packaging specifications, so it is difficult to realize the effective recycling and recycling of packaging materials. On the other hand, due to the lack of a unified standard, it is difficult for the government and the public to 
measure the degree of implementation of environmental enterprises, the government's supervision and management is difficult to effectively implement, and preferential policies are difficult to implement in place.

\subsection{Backward environmental logistics technology and shortage of professional logistics technical talents}

The development of environmental logistics not only depends on the establishment of logistics environmental idea, the formulation and follow of logistics policy, but also depends on the grasp and application of environmental technology. Compared with the developed countries, there is still a certain gap between China and the developed countries in terms of environmental logistics technology. For example, in terms of mechanization, the degree and advanced nature of logistics mechanization are still far from the requirements of environmental logistics. In terms of logistics materials, there is a big gap between the reusability and degradability of environmental logistics, and there are still certain aspects in the automation, informatization and networking of logistics. Gap, these have affected the effective promotion of environmental ecommerce logistics in China. Although the logistics technology of our country has been developing in recent years, there is still a long way to go to reach the standard of environmental logistics.

The key to the development of environmental logistics technology is talents. Compared with traditional logistics, environmental logistics is more advanced and requires higher technology, which requires a large number of professional technology and management talents. Although many universities have set up logistics majors, most of the teaching concepts and contents are relatively old, and the research on environmental logistics is relatively scarce. Students have learned a lot of outdated management theories, but lack of practical operation ability, which can not meet the market demand for environmental logistics talents. environmental logistics talents should master the most advanced logistics technology, have the concept of green environmental protection, and master the knowledge and skills of ecological environment protection and resource utilization. However, the current education level of most colleges and universities can not meet the needs of environmental logistics development for talents. The shortage of professional talents hinders the development of environmental logistics in China.

\section{MEASURESTOIMPROVETHEDEVELOPMENTLEVEL OFENVIRONMENTALE-COMIERCELOGISTICSIN CHINA}

\subsection{Continuously strengthen the development concept of environmental e-commerce logistics}

Concept is a kind of world outlook with fundamental and universal significance, a reflection of certain productivity level, living standard and ideological quality, a guide to people's activities, and it can promote people's behavior to shift and change. For e-commerce logistics enterprises, we should actively promote the concept of environmental development, at the same time, we should improve legislation to restrict their behavior, promote their change of thinking, and establish the concept of environmental ecommerce logistics development. For consumers, we should strengthen the publicity of green environmental protection in the whole society, let consumers know about environmental logistics, establish environmental consumption concepts such as purchasing green environmental protection products, supporting renewable resources products, supporting garbage classification and recycling activities, improve the awareness of environmental consumption, actively participate in environmental logistics, and give full play to the masses to supervise environmental logistics. In fact, consumers' environmental consumption behavior will force enterprises to carry out environmental reform, so as to promote the implementation and popularization of environmental production, environmental packaging and environmental logistics.

\subsection{Give full play to the guidance and supervision functions of the government and guide the environmental development of $e$ - commerce logistics}

In the development of environmental e-commerce logistics, the government should play a leading role. The government shall formulate corresponding environmental laws and regulations, strengthen the management of pollution generation sources in the logistics process by limiting the amount of exhaust gas emissions and noise, establish cross enterprise and cross regional joint organizations by giving full play to the role of the government, implement possible joint distribution, composite consistent transportation and other ways to improve the logistics efficiency and reduce the cost of logistics enterprises[4], and invest funds and taxes through project approval Preferential policies and other policies encourage scientific research enterprises to strengthen technological research, improve the environmental protection of packaging materials, simplify packaging as much as possible, and the recycling level of waste packaging materials, so as to realize the rationalization and 
modernization of packaging; through the adoption of government environmental subsidies, loan discount and other policies, guide enterprises to participate in environmental logistics, so as to comprehensively improve the environmental level of e-commerce logistics in China.

\subsection{Accelerate the establishment of a environmental logistics evaluation system with international level}

The establishment of a environmental logistics evaluation system with international level is an important part of standardizing the environmental logistics industry and promoting the development of environmental logistics [5]. The government should take the lead to work out the evaluation standards of environmental logistics jointly with key enterprises and industry associations, and formulate the standards from the aspects of production, packaging, storage, transportation and circulation. The environmental logistics standard system should be based on the perspective of energy conservation, emission reduction and environmental protection, establish carbon emission standards, determine the carbon emission measurement methods of each logistics link, define the indicators of environmental warehouse, unify and standardize the environmental packaging, and establish a environmental evaluation system of the whole industrial chain. The environmental logistics standard itself should have the international advanced level, and be measurable and operable. Through the formulation and implementation of the environmental logistics standards, the whole logistics industry will be more standardized towards the direction of green environmental protection.

\subsection{Accelerate the cultivation of environmental logistics talents and improve the level of environmental logistics technology}

In the final analysis, the development of environmental logistics and the promotion of logistics technology depend on talents, and the factor of talents is very important [6]. To cultivate environmental logistics talents, we must first make clear the knowledge requirements, ability requirements and quality requirements that environmental logistics talents need to have. We must benchmark the most advanced international technology and experience, formulate a reasonable talent training program, and update the teaching content of the professional follow-up industry, so as to ensure that the students trained meet the requirements of the era of environmental logistics development. In the process of talent training, we should strengthen the integration of the concept of green environmental protection development, so that logistics talents have a stronger sense of environmental protection and social responsibility. In addition, we should strengthen the training of on-the-job logistics talents, increase their knowledge and awareness of color logistics, enhance their enthusiasm and initiative to participate in environmental logistics, and comprehensively promote the environmental process of logistics industry.

\section{CONCLUSION}

In a word, the traditional extensive e-commerce logistics mode will surely be replaced by the development mode of environmental e-commerce logistics. Although there are many deficiencies in the environmental development of ecommerce logistics in China, as long as we establish the correct development concept of environmental ecommerce logistics, give full play to the government's guidance and supervision functions, guide the environmental development of e-commerce logistics, and speed up the development with international level, the development of environmental e-commerce logistics in China will reach the world leading level if we accelerate the cultivation of environmental logistics talents and improve the technology of environmental logistics.

\section{REFERENCES}

[1] National standard logistics terminology of Republic of China (gbvt 18354-2001)

[2] Yang Xiaopeng,Research on China's green logistics activation scheme, Commercial economy, August 2019, pp.67-69.

[3] Zheng Wei, Discussion on the implementation of green logistics management strategy in the low carbon economy environment, Modern economic information, 2019, (06): 382.

[4] Xue Lili, Qiao Linyuan, Research on the path of green development in the field of logistics in China, Value engineering, November 2019, pp.11-12.

[5] Wang Yan, Analysis on green development strategies of e-commerce logistics, Value engineering, November 2019, pp.11-13.

[6] Chen Tao, Liu Pan, Research on the role of green logistics in the development of sharing economy, Business Economic research, June 2019, pp.83-86. 